\title{
Research on Marketing Strategy of Huawei Mobile Phone in European Market
}

\author{
Romans Dmitrijevs \\ Business School, Sun Yat-sen University, Guangzhou, China \\ Email: Romans.dmitrijevs@gmail.com
}

How to cite this paper: Dmitrijevs, $\mathrm{R}$. (2020). Research on Marketing Strategy of Huawei Mobile Phone in European Market. Open Journal of Business and Management, 8, 1138-1150. https://doi.org/10.4236/ojbm.2020.83073

Received: April 5, 2020

Accepted: May 9, 2020

Published: May 12, 2020

Copyright $\odot 2020$ by author(s) and Scientific Research Publishing Inc. This work is licensed under the Creative Commons Attribution International License (CC BY 4.0).

http://creativecommons.org/licenses/by/4.0/

(c) (i) Open Access

\begin{abstract}
At present, telecommunication equipment follows the trend of scientific and technological development and continues to provide a steady stream of power for the promotion of economic and information globalization. Huawei Technologies Co., Ltd. has gradually become a major supplier in China by providing various network solutions for telecom operators. Huawei's mobile phones and other products have also achieved international layout. R\&D institutions, market branches, and joint ventures have been established in many European countries. However, in the face of increasing demand from overseas markets, the fierce competition in the international telecommunications market, and the challenges and opportunities continue to stand out in the context of economic globalization. How Huawei optimizes its existing European brands and implements innovative marketing strategies to form the company's core competitiveness which is a key issue on the road of internationalization. This article mainly researches the current European marketing strategy of Huawei mobile phone products, and puts forward reasonable suggestions.
\end{abstract}

\section{Keywords}

Huawei Mobile Phones, European Marketing, Overseas Markets

\section{Huawei's European Marketing Strategy Status}

\subsection{Price Strategy Status}

Huawei often adopts a fast-penetrating new product pricing strategy, uses low prices and strong promotional efforts to achieve the purpose of quickly occupying the market, and increasing market share and lets foreign consumers accept domestic products with the fastest speed and the shortest time (Jin \& Yin, 2019). According to 2015 data, Huawei's smartphone sales in the five major markets of Spain, France, the United Kingdom, Italy and Germany increased by $123 \%$ in 
2014. At present, Huawei is furthering its development based on the $3 \%$ market share in Spain and Germany and 5\% market share. Its high-end product series $\mathrm{P}$ series and MATE series are gradually shifting from a rapid penetration strategy to a rapid plunder strategy in order to improve the profit of Huawei's mobile phone business and establish a corporate image.

\subsection{Channel Strategy Status}

By providing hardware equipment and communication solutions to many telecommunications companies, Huawei has won great favor from customers. Based on the existing telecommunication operator's channel network and good cooperation relationship, the electronics consumer goods market has been further expanded. Through good cooperation with these channels, Huawei's products have achieved good development in the European market, and ultimately achieved great success. Huawei becomes a household brand in the European market.

Huawei exports its products to major European telecommunications companies through good technology and services, and high-quality communication equipment, and continuously adopts a variety of cooperation channels to stabilize Huawei's position in the European market. There is no doubt that Huawei's channel strategy is very successful. The high level of partner quality and the surge in the number of channel partners are the biggest evidence of its successful channel sales (Jiang, 2017).

The development of Huawei's channel strategy has evolved from "integration" to adhering to this strategy, from "leading innovation" to "joint innovation", from "self-directed" to a fully open ecological construction, and from "self-directed" to "full open" and core PAR. TANA, which has won the channel, is becoming more and more open. Their own actions, attitudes and mentality have attracted cooperation from partners in various fields.

\subsection{Status of Promotion Strategy}

In terms of promotion methods, Huawei uses a variety of promotional methods to achieve market expansion and vigorous promotion of corporate image through sufficient budgets, such as staff selling, business promotion, and advertising.

In terms of advertising decisions in the European market, Huawei has attracted more consumers by hiring local celebrity endorsements and combining advertising slogans with local characteristics, which has finally achieved good results. In addition, Huawei has invested a lot of money in sponsorship, and has sponsored several top European football clubs, and finally realized the expansion of brand influence in the consumer market (Feng, 2019).

In terms of sales decisions, Huawei has achieved better promotion results by directly hiring salespeople from abroad, training personnel in sales promotion management, and improving sales performance and sales promotion design, and good sales performance incentive policies. In the selection of the best employers of global professional social networking sites in 2014, Huawei ranked among the 
best, laying a good foundation for its opening in Belarus, Belgium and other foreign markets (Pan, 2019).

\section{Problems with Huawei's European Marketing Strategy}

\subsection{Unreasonable Price Positioning}

In the initial stage of Huawei, low-cost marketing has once obtained a great advantage in domestic and foreign market competition as a killer. However, with the changes of the times, the development of high-tech fields and low- and medium-cost strategies in competition have become unwise choices, and it is difficult to obtain better market effects. With the continuous improvement of people's economic ability, more and more high-priced and high-quality products are recognized. In the past, domestic mobile phones mainly entered the European mobile phone market to compete for the market share of European low-end mobile phones. Still according to the inertial thinking of competing in the Chinese mobile phone market, through the low price penetration into the European mobile phone market, hoping to gain market share through the advantage of price. And after gaining market share, increasing the price. But the European mobile phone market is not the same as the mobile phone market of developing countries represented by China. Relative to price, European mainstream consumers are more concerned about the quality of products. Therefore, in response to this situation, Huawei must have a new pricing strategy to adapt to the needs of customers in the new era, and to adapt to the development trend of the era, shape itself as a high-end brand image in the European mobile phone market, and develop a set of marketing strategies suitable for its own brand positioning to improve its core competitiveness in the European mobile phone market $(\mathrm{Xu}$, 2019b). In the early stages of Huawei's development, in order to achieve long-term survival and development of the enterprise, maximize the benefits of the enterprise, and continuously improve the image of the enterprise, the break-even pricing method is the pricing strategy chosen by Huawei. After a long period of construction and development, Huawei's overall strength is strong, and its products are unique. By adding quality comparison and competitive price pricing methods to achieve comparisons with competitors in mobile phone product style, performance, quality, and cost, etc. Find the difference between the two and analyze the root cause of the price difference. Through a large amount of market research data, we know that Huawei's precise product market positioning is based on cost. It also clarified the outstanding advantages and characteristics of Huawei products, and used the break-even point as a reference to make the final price of Huawei products clear. Based on the real needs of the target market, Huawei manufactures and develops special products that meet this market. At the same time, it combines the product characteristics of competitors and consumers' attention to the multi-dimensional attributes of the product to determine the uniqueness of the product, so as to achieve accurate market posi- 
tioning. The most critical step is to identify product features that are more advantageous than competitors. Competitive advantages are generally divided into price advantages and consumer preference advantages. By vigorously reducing the unit cost of production products, enterprises can achieve a lower price advantage under the same quality. Or the enterprise may do its utmost to provide highly distinctive product services to satisfy consumers' unique product preferences to realize the advantages of preferences. In the international market, for products and services of NGN and 3G, which have reached the world's leading level compared with competitors, or some products with scarce technology, their prices can be raised according to price competition pricing methods.

\subsection{Single Sales Channels}

As a telecommunications company, Huawei has become a leader in marketing channel management in the early stages of the development of the domestic communications industry. Channel construction has always been an important method of marketing. Different marketing strategies are applicable to different development stages. Huawei has gradually formed a certain scale for a long time, relying on direct sales as its sole sales channel. Against this background, Huawei officially opened up the European market and found that providing product solutions to different customers is a huge demand in the current market. Therefore, it is necessary to change the current direct sales model to conform to the development trend of the times, and finally formed the business model of distributors.

Based on the premise of sales and training partners, service partners, and direct users, Huawei must establish a comprehensive and comprehensive distribution channel platform. End-to-end product integration solutions are the goals and objectives of Huawei. By flattening the sales channels, Huawei has gradually divided the channel functions and industry coverage in detail, so that the relationship between product agents is equal, and they enjoy the same preferential policies. All these depend on the accumulation and turnover of performance, and finally get the benefits brought by Huawei's product performance, brand and service level. Through numerous decisions, Huawei has achieved support and incentives in many aspects such as technical training and marketing to maintain a smooth distribution channel.

\subsection{Limitation of Promotional Methods}

For Huawei, advertising is also a major promotion tool, and there are only a handful of industry media that can cooperate with Huawei in China. Also in the UK market, Huawei has always hired a local veteran advertising company and guided it to release some strategic advertisements. Although it maintains good exchange and communication with the media, it is not a manifestation of a good promotion method. Many foreign magazines have interviewed Huawei, such as 
"Forbes", "Fortune", "Wall Street Journal”, "Financial Times" and so on. After Huawei's products were selected by France's second-largest telecommunications operator, many French media also actively came to interview. Huawei attaches great importance to the shaping and construction of its brand and image, and has established a huge marketing team. The team is the ambassador and spokesperson for the Huawei brand. It can establish a good market reputation and promote an excellent culture on the customer side, but it has a limited role in forming a full range of brand communication and market penetration. We can invite customers and potential customers from all over the world to experience China first-hand, change the Chinese image of the inherent full dress and mandarin jacket era in their hearts, and use the method of peripheral convergence to bring the message "Modern China to high-tech Huawei is an inevitable choice". Pass and communicate to customers.

\section{Huawei's Marketing Strategy Choice}

\section{Huawei's STP Strategy for Overseas Marketing}

1) Segmentation of overseas markets

The overseas market segmentation is the process of subdividing the entire overseas market into multiple sub-markets with different products and market combinations according to different segmentation criteria. The markets with the largest revenue estimates are selected for development. The international market for industrial products is segmented according to factors such as user size, end users, purchasing organization characteristics, and purchasing power. In view of the special nature of the international mobile communications market, the foreign telecommunications market is divided into European markets, American markets, Asia Pacific, Middle East and Africa. There are many differences between industry and telecomunications markets. Specifically, the characteristics of each market segment are shown in Table 1.

2) Choice of target market

The target market is to select the most suitable market based on the development of the company under the fact that it cannot meet the needs of all consumers. In accordance with Huawei's global strategy, the European market is the main target market, and different market competition strategies are selected for different countries. Not only can Huawei give full play to its own advantages, it can also gradually enhance $4 \mathrm{G}$ performance to meet the needs of customers in different types of markets. At the same time, it can also greatly increase the proportion of enterprises in foreign markets, and promote the total production of enterprises to achieve the advantage of reducing costs and improving efficiency.

According to Huawei's international development history, it is not difficult to see that Huawei's international development order is from developing countries to developed countries. First, based on the development of the domestic market, focus on research and development, cultivate its own unique professional and 
Table 1. Features of Huawei's overseas segments.

\begin{tabular}{|c|c|c|c|c|}
\hline \multirow{2}{*}{ Market characteristics } & \multicolumn{4}{|c|}{ Market segments } \\
\hline & European Market & Americas Market & Asia Pacific Market & African market \\
\hline Product demand & Big & Middle & Big & Small \\
\hline Market potential & Great & Big & Great & Middle \\
\hline Purchase frequency & High & Middle & Middle & Low \\
\hline Average order size & Great & Great & Bigger & Big \\
\hline Market entry difficulty & Big & Big & Bigger & Bigger \\
\hline Number of suppliers & Many & Many & Many & Less \\
\hline Price & Not sensitive & Less sensitive & Sensitive & Sensitive \\
\hline $\begin{array}{l}\text { Product quality } \\
\text { requirements }\end{array}$ & High & High & High & High \\
\hline $\begin{array}{c}\text { Reliability and } \\
\text { stability requirements }\end{array}$ & High & High & High & High \\
\hline Functional requirements & New, complete & New, complete & Complete & Complete \\
\hline $\begin{array}{c}\text { Maintenance } \\
\text { timeliness requirements }\end{array}$ & High & High & High & High \\
\hline
\end{tabular}

Source: Yao Tian. Research on Huawei's Overseas Market Strategy [D]. Beijing: University of International Business and Economics, 2012.

technical capabilities, then use developing countries as a springboard to form a certain influence in the international community, and finally target the European market and strive to occupy the markets of developed countries A certain market share to realize its own value. Therefore, Huawei adopted a strategy of "easy first and then difficult". The target market economic development level and technology level selected by it are lower than domestic, and the second is to adopt a climbing strategy. The selected target market economic development level and technology level are higher than domestic. Huawei finally aimed at the European market to maintain the speed of innovation and keep up with the development of cutting-edge technologies. It can give its own technical strength a greater advantage in development, and can also accelerate the return of funds, providing sufficient guarantee and support for subsequent technology research and development.

3) European market positioning

The choice of target markets has been established, and then Huawei's position in these markets must be determined. Product positioning must make it different from competitors' products and reflect product differences. Huawei has accurately positioned $4 \mathrm{G}$ broadband network solutions (mobile switching systems, base station systems, $4 \mathrm{G}$ mobile phones) as its products.

Foreign manufacturers have an absolute advantage in the European market, but Huawei has passed many severe tests in the European market, proving that Huawei's $4 \mathrm{G}$ products are not inferior in technology to foreign manufacturers. 
And with many advantages such as higher cost, smooth channels, and timely service, compared with foreign manufacturers with technical advantages, Huawei has a certain competitive strength, especially the cost performance of products and the technical support capabilities of enterprises. Figure 1 shows the actual location of Huawei's European market. Ericsson has stronger technical support capabilities, but the high price leads to the lowest cost performance. Nokia is in the middle. Huawei's competitive advantage lies in the highest cost performance.

Based on an in-depth analysis of the European market, I believe that Huawei should position its products in the European market as "meeting the needs of customers, quality products and services", that is, always oriented to customer needs, with its cost-effective and good after-sales service. At the same time, strengthen relations with local operators (Yi, 2019). The cooperation of all parties has gradually established Huawei's international brand image, and gradually entered and expanded Huawei's market share in the region.

\section{Huawei's European Marketing Strategy Recommendations}

\subsection{Price Strategy Recommendations}

1) Formulate different price strategies for different markets

In the price competition in overseas markets, the use of low-cost strategies will often open the market quickly, but at the same time will quickly fall into a price war. Taking into account factors such as comprehensive price positioning,

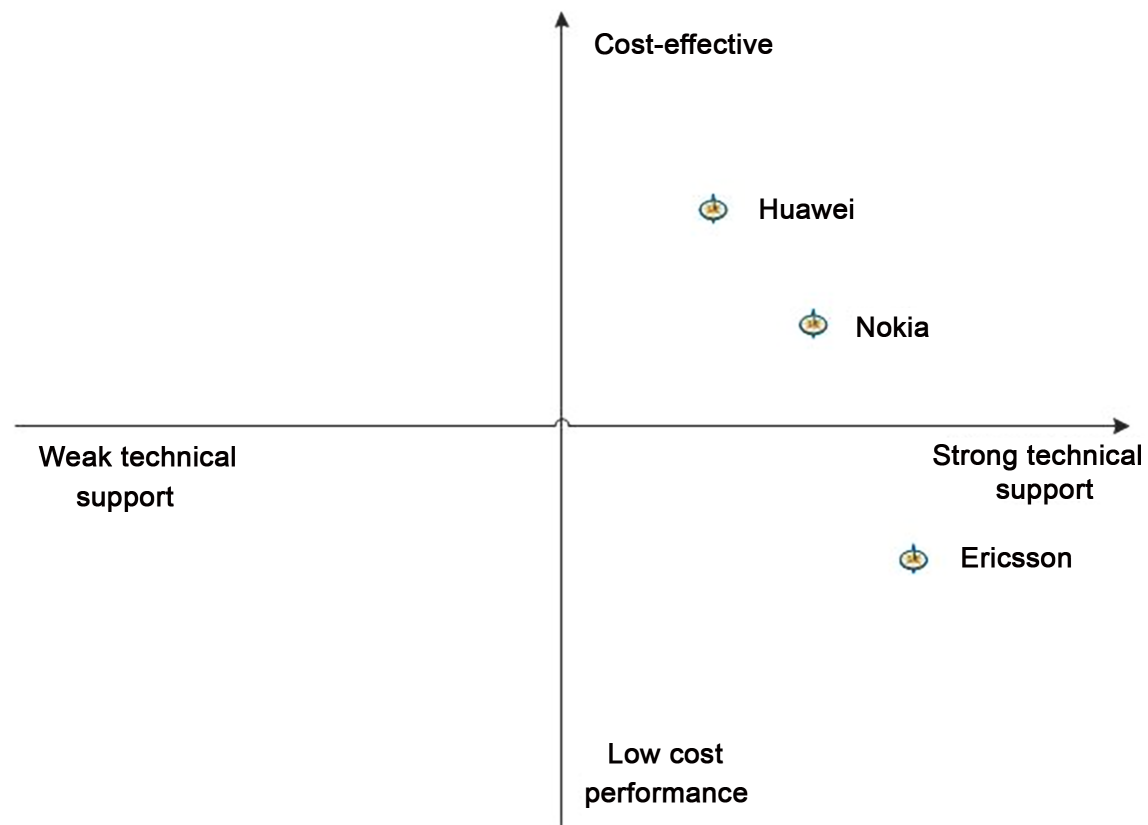

Figure 1. The actual location of Huawei's European market. Source: Feng Bo. Huawei Technologies Co., Ltd. European Marketing Strategy [D]. Jilin University of Finance and Economics, 2019. 
flexible use of price strategies can effectively improve the price competitiveness of enterprises and avoid the vicious circle of price competition. In the European market, Huawei should use its own technical team to learn the world's top technology, improve product autonomy, seize market demand, create product brand value, use technology to improve production efficiency, reduce production costs, increase product profits, and increase labor productivity. Make the cost of the enterprise lower than the average cost of the same industry. What's more important is to consider the factors of competitors, that is, to identify and comply with market entry requirements and price ceilings set by corporate costs. In price competition, the formulation of a price strategy should be proactive, that is, actively determine the price based on the actual situation of the company's products and the differences in product competition. Ensuring that enterprises can master and control competition autonomy in market price competition.

2) Market pricing method

Huawei is based on the cost-plus pricing method, but this pricing needs to pursue market pricing, which inevitably lacks flexibility. It is suggested that the pricing strategy of the European market should be improved based on the cost-plus pricing method.

First, pricing varies according to regional differences. Different countries have different levels of economic development, consumers' acceptance of product prices is inconsistent, and the competition situation of competitors is inconsistent. The price standards of communications products in different countries are very different. Huawei needs to analyze the economic development of different countries, assess the product demand capabilities of each market, collect and analyze competitors' quotes, and then formulate different market price system standards (Li, 2020).

Second, pricing is based on product life cycle differences. Products include four stages of introduction, growth, maturity and decline. Different pricing strategies can be used at different stages. During the product introduction period, a high-price obsolete pricing strategy can be adopted. During the growth and maturity period, a penetrating pricing strategy can be adopted to occupy market share and maximize market profit. During the recession, inventory can be cleared directly to increase sales prices (Xiao, 2019).

\subsection{Channel Strategy Recommendations}

1) Select the appropriate channel model

When choosing a marketing channel, Huawei should fully consider the current status of the marketing environment and the direction of future changes, so that the selected channel can flexibly adapt to changes in the international market environment. According to Huawei's development status in the European market, Huawei should adopt its own strategy and adopt the channel model of commissioning agent to establish its own sales organization.

First, find the right middleman. As shown in Figure 2, if the middleman is 


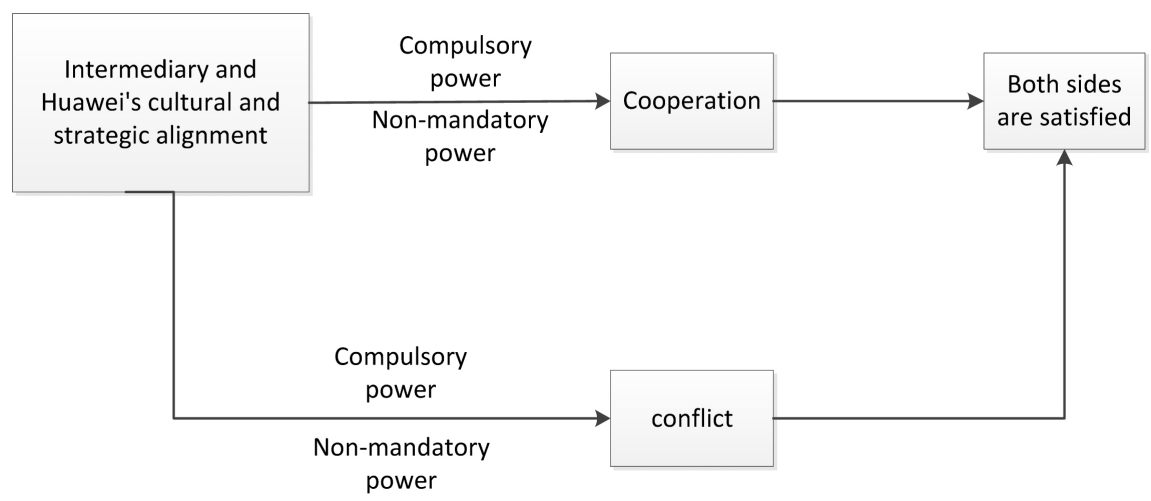

Figure 2. Cross-cultural channel behavior.

consistent with Huawei in terms of culture and strategy, it will reach a satisfactory cooperation and become a long-term partner of Huawei, which can enhance Huawei's market competitiveness. Of course, if there are differences in the culture and strategy of the selected middleman and Huawei, there will inevitably be a "conflict of interest" between the two, which will eventually lead to the failure of the cooperation between the two parties.

So, choose middlemen who are the same in terms of culture and strategy. Culture and strategy are consistent in the following aspects: first, to recognize Huawei's companies and products; second, to implement Huawei's business philosophy, management methods, working methods and business models; and third, to be willing to implement Huawei's marketing strategies.

2) Build channels by yourself

If Huawei has its own overseas sales agency, it will be easier to study the local market and its marketing activities will be more appropriate. In addition, in the European market, non-price competition is becoming increasingly important. In particular, the implementation of instalments, fast delivery, acceptance of small orders, and enhanced after-sales services make the distribution channel more important (Xu, 2019a). Especially in the telecommunications industry, customers often consider their after-sales service as an important consideration when deciding whether to choose Huawei products. Intermediaries, due to the underwriting of various products, it is difficult to provide a complete service process for each product, so the market cannot develop smoothly. Therefore, Huawei's creation of its own distribution channel is the only way to expand its market.

3) Timely adjustment of channel system

When consumers' purchase methods change, the market expands, products enter different life cycles, new competitors rise, and new marketing models emerge, multinational companies will modify and improve the organizational structure of the entire channel system according to market changes.. In this case, adding or removing some intermediary agencies will always maintain the overall efficiency of the channel. Huawei has a successful "overall channel concept" in its marketing channels, that is, the process of reaching the consumer terminal is an organic whole, and each link must meet the requirements. The coordinated 
effort of channel members is a decisive factor for the effective delivery of Huawei's final market. If an intermediary is incompetent, no matter how difficult it is for other intermediaries to work, the overall efficiency of the channel will be affected. Therefore, Huawei encourages and advocates cooperation and competition between members of different stakeholder channels to avoid conflicts. If you pay too much attention to your own interests, it will destroy the cohesion and image of the channel, and ultimately fail.

\subsection{Promotion Strategy}

1) Choice of standardization or localization strategy for international advertising

When Huawei's products entered the early European market, advertising was usually the leader and sole representative. It can help Huawei and its products establish a unified image in the European market. Generally, the standardization of advertising can effectively reduce costs, and to a large extent, it can well implement and control overall promotion goals. However, due to a variety of constraints, especially the large differences between local and domestic customer needs, the application of local promotion strategies can make the promotion more targeted, and if the effect is good, it can effectively drive sales a large amount of growth, and ultimately hope to obtain greater economic profits.

2) Flexible employment promotion

Personnel promotion is an indispensable means of promotion in international marketing. It has the advantages of strong selectivity, high flexibility, ability to transmit complex information, effectively stimulate customers' desire to buy, and obtain market feedback. It is an indispensable means of promotion in international marketing (Zhou, 2018). Specifically, we can organize and translate relevant information, complete a set of manuals and tenders as soon as possible in accordance with international practices and standards, and produce related promotional materials to make it as perfect as possible.

First, ensure data integrity and continuity. We can regularly send the latest information to existing or potential users to allow customers to experience Huawei's "customer-oriented" concept and integrate the concept of quality service into foreign work.

Secondly, the product department is organically integrated with foreign countries. The establishment of an overseas joint action team must first understand the situation in key areas, then formulate an action plan, send personnel to various parts of the country, and prepare for permanent residence. Product marketing staff and customers actively communicate with each other to keep the information flowing and conduct regular product training.

Third, given the differences between the European and domestic markets, we should take into account the characteristics of China, China's relations with these countries, and the overseas situation, and take advantage of the relationships between the embassies of the countries in the market in China. In areas 
where demand is unclear, relocation of test bureaus or original equipment can be provided to the country or community to guide the needs of the project.

Fourth, due to the different requirements of technical bidding and testing standards, the product department has established a deep technical support team as a strong market support.

3) Establish the image of Huawei through the exhibition

Exhibiting is an important means of disseminating corporate brand image and product. Every time Huawei enters a new market, it will host a grand exchange show there. It can be said that the exhibition is a place for Huawei to display its brand image and also a stage to surpass its opponents. How to use the exhibition to show the prospects of operators and show high-level strength to ordinary visitors and professionals should be the real purpose of operators participating in the exhibition. In the booth, not only products, services and applications should be displayed, but also the motivation of the enterprise. The competitors are close to each other, and even if they just do a little better, they will form a strong contrast in front of the audience. Huawei should give every exhibitor a deep impression to establish their personal and corporate image.

\section{Conclusion}

The first thing Chinese enterprises should pay attention to when promoting the world is the promotion of national image and corporate culture. We can see from Huawei's development process that in the early days, Huawei invested huge amounts of money to build a national image, promote corporate culture, and create a brand effect, paving the way for it to open the European market. At present, the problem that our products face in the international market is low prices. Some domestic enterprises are eager to seek short-term interests, abandon the construction of their own brands and channels, and choose OEM to process for others. If Chinese enterprises want to get out of this dilemma, they should carry out independent marketing, build their own brands and establish their own marketing channels. Only in this way can Chinese enterprises gain a firm foothold in the international market and benefit for a long time. Through in-depth analysis of various types of data and theoretical research, the following conclusions are drawn.

First, in terms of market positioning, the European market should be positioned as "quality products and super services to meet customer needs". Serving customers is the only reason for Huawei's existence. Customer demand is the driving force behind Huawei's development.

Secondly, in terms of price, Huawei's goal in pricing in the European market is to "not disrupt the market through price wars and to win with high-quality services", to maximize the company's long-term profits. In the European market, market-oriented pricing strategies should be adopted. In terms of products, competitive prices, stable products, high-quality services and the rapid expansion of market share, as well as the scale efficiency of products, and the price 
advantage should be maintained to expand the market size.

Third, in terms of channels, according to the current status of Huawei in the European market, Huawei should combine its own strategy and adopt a channel model of entrusted agency to establish its own sales organization. In addition to the design of the distribution channel model in the European market, Huawei should also strengthen channel management and control in order to seek mutual support and friendly cooperation between the company and intermediaries. Channel management includes correct tracking, monitoring and evaluation of intermediaries, guidance and encouragement of intermediaries, and timely adjustment of the channel system.

Fourth, based on Huawei's current promotion strategy in major European market segments, Huawei should also use international advertising standardization or local strategy choices to make good publicity, flexibly adopt personnel promotion methods, and establish Huawei's image through exhibitions, to make full use of public relations policies.

\section{Acknowledgements}

Thanks to my teachers and classmates. You gave me a lot of inspiration and suggestions for my thesis, and gave me a lot of confidence. Wish all teachers and classmates a smooth job.

\section{Conflicts of Interest}

The author declares no conflicts of interest regarding the publication of this paper.

\section{References}

Feng, B. (2019). Research on European Marketing Strategy of Huawei Technologies Co. Ltd. Master Thesis, Changchun: Jilin University of Finance and Economics.

Jiang, Z. Q. (2017). Research on Marketing Strategy of Huawei Mobile Phone. Modern Business, 36, 16-17.

Jin, S. H., \& Yin, R. (2019). Research on Overseas Marketing Strategies of Domestic Smartphones. Technology and Market, 26, 189-190.

Li, W. J. (2020). Talking about the Problems and Countermeasures in the Marketing of State-Owned Enterprises. Chinese and Foreign Entrepreneurs, 10, 82-83.

Pan, Z. C. (2019). Promotional Strategy Becomes a Powerful Means of Market Competition. Agricultural Machinery Market, 7, 25-26.

Xiao, M. Y. (2019). Huawei Mobile Phone Product Life Cycle and Marketing Strategy Analysis. Science and Fortune, 6, 165.

$\mathrm{Xu}, \mathrm{Q}$. Z. (2019a). Non-Price Competition Strategy Analysis of Marketing Behavior. Operator, 33, 83.

Xu, Y. (2019b). Research on the Marketing Strategy of Huawei Mobile Phones in the European Market. Master Thesis, Lanzhou: Lanzhou University of Finance and Economics.

Yi, X. (2019). Research on Overseas Marketing Strategy of Huawei’s Carrier Business. 
Lanzhou: Lanzhou Jiaotong University.

Zhou, Z. Z. (2018). Research on Huawei's International Marketing Strategy. Changchun: Jilin University. 